\title{
Symbols and conventions
}

Reference years Where, because of space constraints, a choice of years has to be made, the most recent year or a run of recent years is shown together with the past population census years (2001, 1991, 1981, etc) and sometimes the mid-points between census years (1996, 1986, etc). Other years may be added if they represent a peak or trough in the series.

Financial year

For example, 1 April 2006 to 31 March 2007 would be shown as 2006/07.

Academic year

For example, September 2006 to July 2007 would be shown as 2006/07.

Combined years

For example, 2004-07 shows data for more than one year that have been combined.

Geography Where possible Social Trends uses data for the UK as a whole. When UK data are not available, or data from the constituent countries of the UK are not comparable, data for Great Britain or the constituent countries are used. Constituent countries can advise where data are available that are equivalent but not directly comparable with those of other constituent countries.

Units on tables Where one unit predominates it is shown at the top of the table. All other units are shown against the relevant row or column. Figures are shown in italics when they represent percentages.

Rounding of figures

In tables where figures have been rounded to the nearest final digit, there may be an apparent discrepancy between the sum of the constituent items and the total as shown.

Provisional and estimated data

Some data for the latest year (and occasionally for earlier years) are provisional or estimated. To keep footnotes to a minimum, these have not been indicated; source departments will be able to advise if revised data are available.

Billion This term is used to represent one thousand million.

Household reference person

Sometimes it is necessary to select one person in a household to indicate the general characteristics of the household. For this purpose the household reference person has replaced the head of household in all government-sponsored household surveys after 2000-01. The household reference person is identified during the interview and is:

a. the householder (in whose name the accommodation is owned or rented); or

b. in households with joint householders, the person with the highest income or, if both householders have the same income, the oldest householder.

Seasonal adjustment

Unless otherwise stated, unadjusted data have been used.

Dependent children

Those aged under 16 , or single people aged 16 to 18 who have not married and are in full-time education unless otherwise indicated.

State pension age (SPA) The age at which pensions are normally payable by the state pension scheme, currently 65 for men and 60 for women.

EU Unless otherwise stated, data relate to the enlarged European Union of 27 countries (EU-27) as constituted since 1 January 2007. EU-25 refers to the 25 members of the EU before enlargement in May 2004 from the 15 original members (EU-15).

Ireland Refers to the Republic of Ireland and does not include Northern Ireland. 
Sources Sources are usually listed as the name by which the source is currently known. In some instances, requests have been made to show the source name at the time the data were compiled. Specific instances have been recorded in relevant appendix entries.

Symbols The following symbols have been used throughout Social Trends:

.. not available not applicable

* data have been suppressed to protect confidentiality

- negligible (less than one-half the final digit shown)

0 nil 